\title{
Delayed repair of right atrial isomerism with obstructed total anomalous pulmonary venous drainage by hybrid stent insertion between the left-sided atrium and pulmonary venous confluence
}

\author{
Rajiv R. Chaturvedi, MD, PhD, Glen S. Van Arsdell, MD, Frederic Jacques, MD, and Kyong-Jin Lee, MD, \\ Toronto, Ontario, Canada
}

Surgical repair of right atrial isomerism with obstructed total anomalous pulmonary venous drainage (TAPVD) in the

From the Labatt Family Heart Centre, Hospital for Sick Children and University of Toronto, Toronto, Ontario, Canada.

Disclosures: Authors have nothing to disclose with regard to commercial support.

Received for publication July 5, 2011; revisions received Oct 1, 2011; accepted for publication Dec 8, 2011; available ahead of print March 1, 2012.

Address for reprints: Glen S. Van Arsdell, MD, Labatt Family Heart Centre, Hospital for Sick Children, 555 University Avenue, Toronto, Ontario M5G 1X8, Canada (E-mail: glen.vanarsdell@ sickkids.ca).

J Thorac Cardiovasc Surg 2012;144:271-3 $0022-5223 / \$ 36.00$

Copyright (C) 2012 Published by Elsevier Inc. on behalf of The American Association for Thoracic Surgery

doi:10.1016/j.jtcvs.2011.12.056 neonatal period is associated with frequent recurrence of pulmonary venous obstruction and high mortality. ${ }^{1,2}$ Delay of surgical repair can improve the outcomes. ${ }^{3-5}$ This is the first report of a novel nonpump relief of obstructed TAPVD by insertion of a stent between the left atrium and pulmonary venous confluence.

\section{CASE REPORT}

A male neonate with right atrial isomerism, complete atrioventricular septal defect with moderate atrioventricular valvular regurgitation, pulmonary atresia, right aortic arch, and infradiaphragmatic TAPVD underwent a left modified Blalock-Taussig shunt at 2 days of age. Postoperative
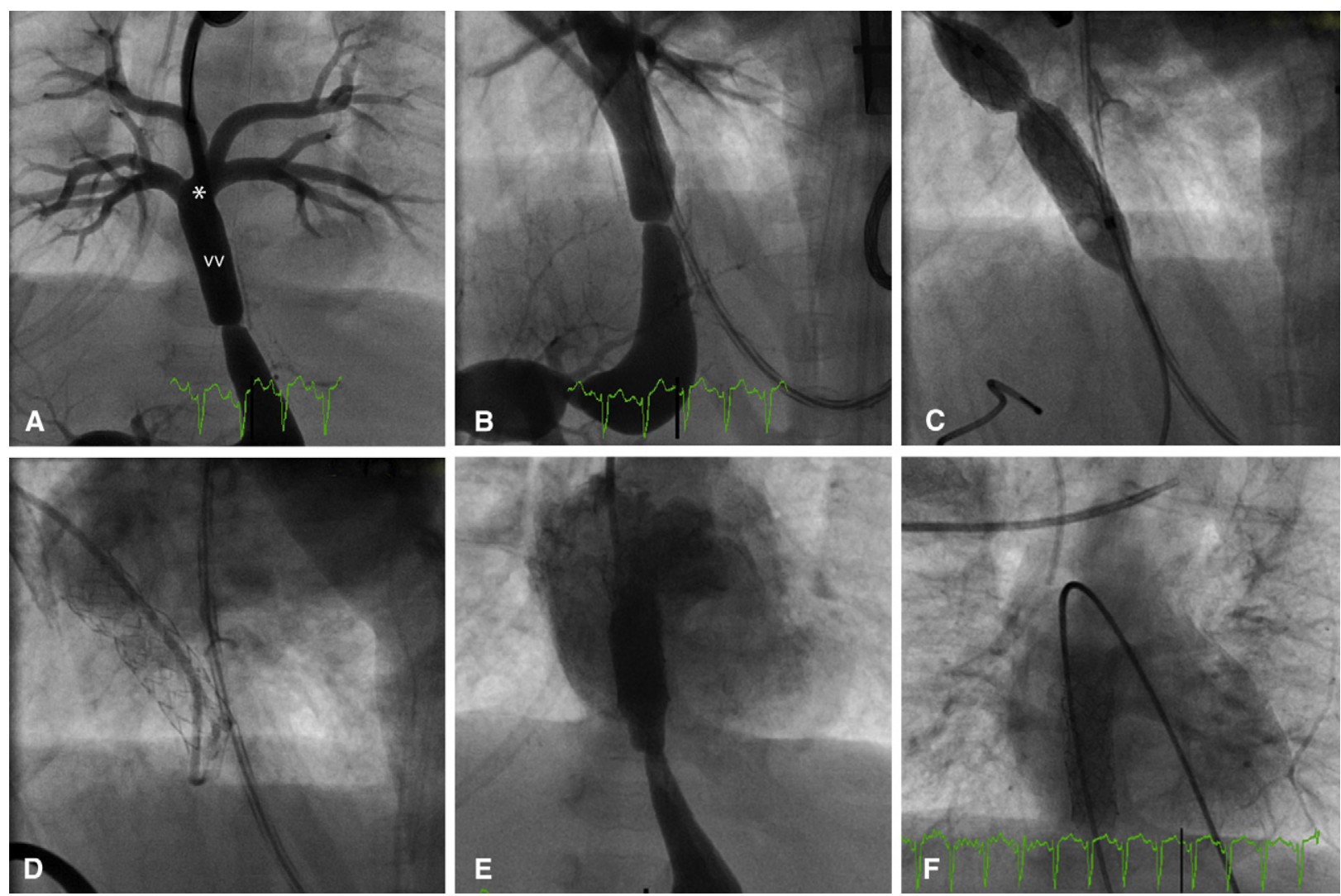

FIGURE 1. Angiographic images of stent implantation from posterior pulmonary venous confluence to left-sided atrium. A and B, Anterolateral projection of infradiaphragmatic total anomalous pulmonary venous drainage with obstruction at level of diaphragm and portal vein insertion. C, Lateral projection of stent at beginning of balloon inflation. D, Lateral projection of fully expanded stent. E, Anterolateral projection of angiogram after stent implantation. $\mathrm{F}$, Angiography through Blalock-Taussig shunt demonstrating pulmonary venous return into stent. *Pulmonary venous confluence. $v v$, Vertical vein. 
complications included cardiac tamponade, wound infection, and serious parainfluenza virus infection, and he remained dependent on the ventilator. Echocardiograms to assess the degree of pulmonary venous obstruction were performed a minimum of every 5 days. The vertical vein had obstructions at its connection to the portal vein and as it crossed the diaphragm (Figure 1). The mean Doppler gradient was initially 1 to $6 \mathrm{~mm} \mathrm{Hg}$ for at least 21 days but increased to $14 \mathrm{~mm} \mathrm{Hg}$ on day 26 at the latter site. At 34 days of age $(3.6 \mathrm{~kg})$, the oxygen saturation had decreased to the $50 \%$ to $60 \%$ range. The patient underwent an attempt at stent implantation through a median sternotomy in our hybrid suite with cardiopulmonary bypass on standby. Using transesophageal echocardiographic guidance, a 20-gauge needle with a check flow was deployed through the roof of the common atrium and used to pierce the back wall of the atrium, enter the posterior pulmonary venous confluence below the entry site of the pulmonary veins, and deliver a 0.014-in guidewire (Figure 1). A pursestring suture was made around the entry site, and a $6 \mathrm{~F}$ Cordis sheath was advanced into the pulmonary venous confluence over the guidewire, under fluoroscopic guidance. Over a 0.035 in wire, a premounted stent $(8 \mathrm{~mm}$ in diameter by $29 \mathrm{~mm}$ in length; Genesis) was delivered to extend from the vertical vein above the proximal stenosis to below the roof of the left-sided atrium, with approximately $2 \mathrm{~cm}$ of the stent in the vertical vein/pulmonary venous confluence and 0.5 to $1 \mathrm{~cm}$ within the left-sided atrium. The stent allowed the pulmonary venous return to enter through its upper surface and drain into the left-sided atrium (Figure 2). The pressure in the pulmonary venous confluence decreased from 37 to $10 \mathrm{~mm} \mathrm{Hg}$ mean after stent deployment. Echocardiography and angiography confirmed that the pulmonary venous drainage was unobstructed. Approximately 2 hours later, the patient developed progressive cyanosis and low cardiac output. He was supported with extracorporeal membrane oxygenation for 4 days and extubated 3 days later. He was discharged from the hospital 72 days later with a $5 \mathrm{~mm}$ $\mathrm{Hg}$ mean Doppler gradient across the stent. The oxygen saturation was in the high 70s. His therapy was continued with enoxaparin, aspirin, and clopidogrel.

During follow-up, an $11 \mathrm{~mm} \mathrm{Hg}$ mean Doppler gradient was observed across the stent, along with left upper pulmonary vein flow acceleration. At 106 days, he underwent preGlenn cardiac catheterization with an oxygen saturation of $72 \%$ to $80 \%$. The pulmonary artery pressure was $15 \mathrm{~mm}$ $\mathrm{Hg}$, a transpulmonary pressure gradient into the lumen of the stent of $8 \mathrm{~mm} \mathrm{Hg}$, and a pulmonary vascular resistance of 1.9 Woods units $/ \mathrm{m}^{2}$. The vertical vein below the stent had involuted.

At 138 days, he underwent stent removal, a bidirectional cavopulmonary connection, and sutureless repair of the

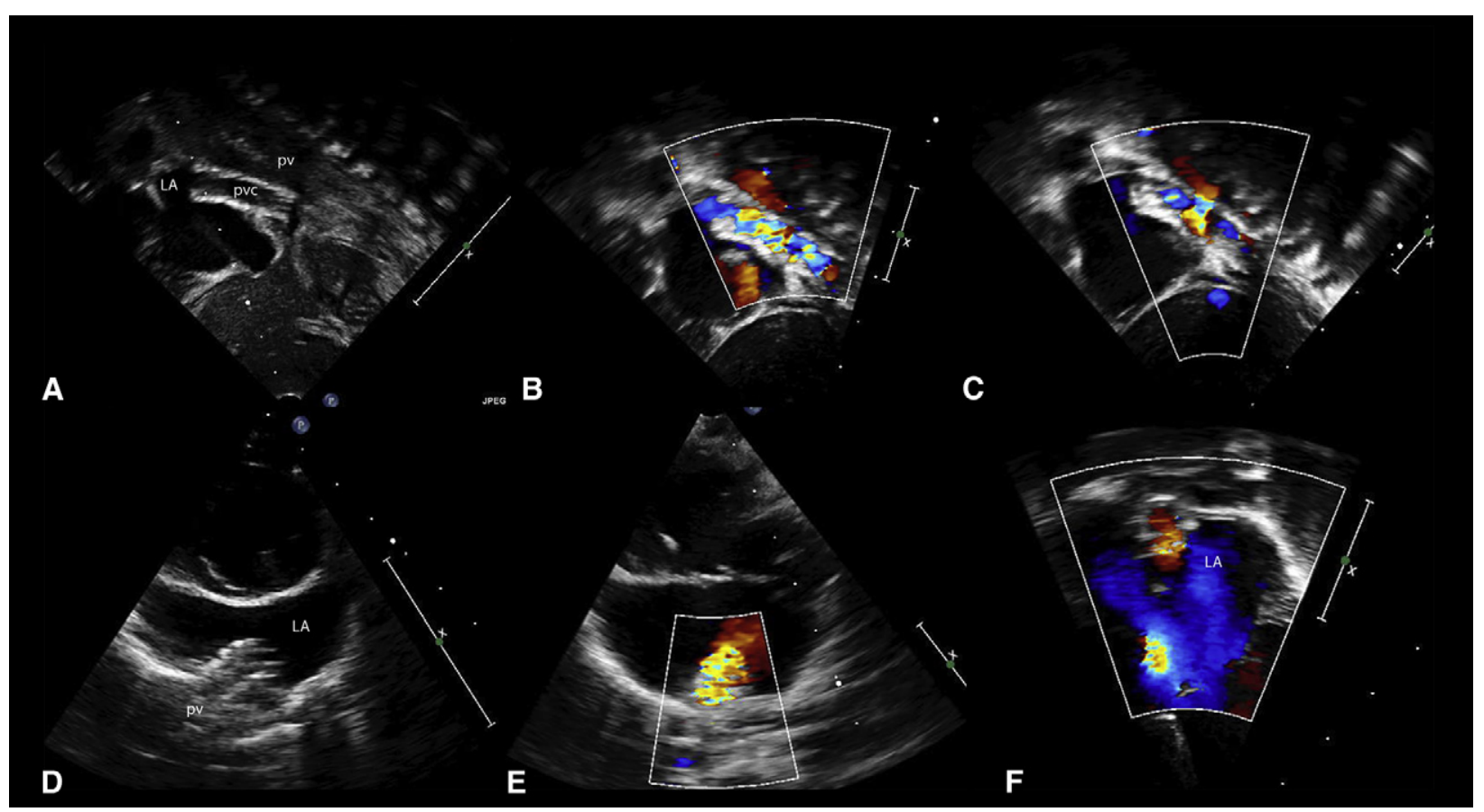

FIGURE 2. Echocardiographic images of flow from posterior pulmonary venous confluence through stent struts into left-sided atrium. A, Subcostal left axial oblique 2-dimensional view. B, Color flow image of A. C, Subcostal left axial oblique image of pulmonary veins draining into pulmonary venous confluence through stent struts. D, Parasternal short axis view of stent from pulmonary venous confluence to left-sided atrium. E, Color flow image of D. F, Four-chamber view of flow from pulmonary venous confluence to left-sided atrium. $L A$, Left atrium; $p v c$, pulmonary venous confluence; $p v$, pulmonary veins. 
pulmonary veins. The mean Glenn pressure was $15 \mathrm{~mm} \mathrm{Hg}$, and transesophageal echocardiography showed unobstructed pulmonary veins. There was extensive cellular ingrowth into the stent at the vertical vein end, but the pathway for pulmonary venous flow remained open. He had initially poor ventricular function and severe atrioventricular valvular regurgitation and cyanosis (oxygen saturation in the high 60 s to low 70s). A positive bubble study led to cardiac catheterization 7 days postoperatively. The Glenn pressure was $12 \mathrm{~mm} \mathrm{Hg}$ with a transpulmonary gradient of 5 $\mathrm{mm} \mathrm{Hg}$ and right ventricular end diastolic pressure of $8 \mathrm{~mm}$ $\mathrm{Hg}$. The Glenn circuit was unobstructed but severe stenosis was present in the left upper pulmonary vein, although with good drainage from the left middle and lower pulmonary veins and right veins. A venous collateral was coil occluded with subsequent increase in saturation from the 50s, while intubated, to greater than $70 \%$, when extubated the next day. He was extubated 9 days after the Glenn procedure and discharged 23 days after surgery. His oxygen saturation at discharge was $75 \%$ to $80 \%$ in room air. At 9 months of age, the oxygen saturation was $88 \%$, and echocardiography demonstrated good ventricular function, moderate atrioventricular valvular regurgitation, unobstructed right upper and lower and left lower pulmonary veins. The mean gradient across the left upper pulmonary vein was $5 \mathrm{~mm} \mathrm{Hg}$.

We believe delaying repair of the TAPVD until the Glenn procedure permitted survival of this patient, albeit with the left upper pulmonary vein stenosis. Although an uncovered stent was used, we believe a seal around the stent was made by the cuff of tissue created around the stent when it was inflated combined with the adhesions around the heart after the previous shunt surgery. We remain vigilant about his pulmonary veins, although this has been a good early outcome.

\section{References}

1. Hashmi A, Abu-Sulaiman R, McCrindle BW, Smallhorn JF, Williams WG Freedom RM. Management and outcomes of right atrial isomerism: a 26-year experience. J Am Coll Cardiol. 1998;31:1120-6.

2. Sinzobahamvya N, Arenz C, Reckers J, Photiadis J, Murin P, Schindler E, et al. Poor outcome for patients with totally anomalous pulmonary venous connection and functionally single ventricle. Cardiol Young. 2009;19:594-600.

3. Yun T-J, Al-radi OO, Adatia I, Caldarone CA, Coles JG, Williams WG, et al. Contemporary management of right atrial isomerism: effect of evolving therapeutic strategies. J Thorac Cardiovasc Surg. 2006;131:1108-13.

4. Wong TH, Yoo S-J, Lee K-J. Implantation of drug-eluting stents for relief of obstructed infra-cardiac totally anomalous pulmonary venous connection in isomerism of the right atrial appendages. Cardiol Young. 2008;18:628-30.

5. Jhang W-K, Chang Y-J, Park C-S, Oh Y-M, Kim Y-H, Yun T-J. Hybrid palliation for right atrial isomerism associated with obstructive total anomalous pulmonary venous drainage. Interact Cardiovasc Thorac Surg. 2008;7:282-4.

\title{
A new method to fenestrate the Fontan circulation
}

\author{
René Prêtre, MD, ${ }^{\mathrm{a}}$ Hitendu Dave, MD, ${ }^{\mathrm{a}}$ Christoph Mueller, MD, ${ }^{\mathrm{a}}$ Katja Kassem, MD, ${ }^{\mathrm{a}}$ and \\ Oliver Kretschmar, MD, ${ }^{\mathrm{b}}$ Zurich, Switzerland
}

Fenestration of the Fontan circulation helps maintain cardiac output while reducing venous and lymphatic pressure, but at the expense of arterial saturation. Although some teams perform it routinely to reduce the amount and duration of cavity transudate, the majority resort to it selectively. ${ }^{1}$

The conventional fenestration involves a 4-mm connection between the Fontan tunnel (intracardiac or extracardiac) and the right atrium created using a kissing technique. Some

\footnotetext{
From the Division of Congenital Heart Surgery ${ }^{\mathrm{a}}$ and Division of Pediatric Cardiology, ${ }^{\mathrm{b}}$ University Children's Hospital, Zurich, Switzerland.

Disclosures: Authors have nothing to disclose with regard to commercial support.

Received for publication June 12, 2011; revisions received Sept 5, 2011; accepted for publication Dec 8, 2011; available ahead of print March 15, 2012.

Address for reprints: René Prêtre, MD, Division of Congenital Heart Surgery, University Children's Hospital, Steinwiesstrasse 75, CH-8032 Zurich, Switzerland (E-mail: rene.pretre@kispi.uzh.ch).

J Thorac Cardiovasc Surg 2012;144:273-5

0022-5223/\$36.00

Copyright (c) 2012 by The American Association for Thoracic Surgery

doi:10.1016/j.jtcvs.2011.12.057
}

fenestrations close spontaneously, but many are obturated secondarily by a diabolo-shaped device inserted percutaneously. ${ }^{2}$ This report describes a new technique of fenestration using an innominate vein to right atrial appendage shunt that can be performed post-cardiopulmonary bypass (CPB) under reliable hemodynamic conditions, offering more possibilities of late percutaneous flow regulation.

\section{CLINICAL SUMMARY}

All 27 patients receiving this type of fenestration since its first realization in January 2005 were included (20052010). Informed consent and institutional review board approval were obtained. At the beginning of this experience, the classic kissing fenestration was also occasionally used until we had the impression that the new fenestration technique was more appealing.

The median age was 30 (22-191) months, and median weight was $13(10-50) \mathrm{kg}$. The driving ventricle was a single left ventricle in 14 patients, right ventricle in 11 patients, and biventricle in 2 patients. 